\title{
The efficacy and safety of intra-articular injection of triamcinolone acetonide versus triamcinolone hexacetonide for treatment of juvenile idiopathic arthritis
}

Shiri Rubin ${ }^{1,2}$, Orly Ohana ${ }^{2,3}$, Ori Goldberg ${ }^{2,4}$, Orit Peled ${ }^{5}$, Yulia Gendler ${ }^{6}$, Zohar Habot-Wilner ${ }^{2,7}$, Yoel Levinsky ${ }^{2,8}$, Rotem Tal ${ }^{2,9}$, Liora Harel ${ }^{2,9}$ and Gil Amarilyo ${ }^{2,9^{*}}$ (i)

\begin{abstract}
Objectives: Juvenile idiopathic arthritis (JIA) is the most common childhood rheumatic disease. Intra-articular corticosteroids joint injection (IAJI), with triamcinolone hexacetonide (TH) or triamcinolone acetonide (TA), is an effective additional treatment for oligo and polyarticular JIA. Previous studies have shown the benefits of TH over TA; however, TA is still used in many pediatric rheumatology centers. Our unit has experience with both regimens, and therefore we aimed to compare the efficacy and safety of TA versus TH for JIA patients.

Methods: Chart review of JIA patients who were randomly (based on drug availability) treated with TA or TH IAJ during 2010-2019. Primary outcomes for efficacy were defined as full recovery from arthritis one month after IAJ and a relapse rate of arthritis 3 months after IAJI. Primary outcome for safety was defined as the occurrence of adverse events (AEs) during the follow up period after IAJI.

Results: Overall, 292 joints of $102 \mathrm{JIA}$ patients were treated (138 TA/154 TH joints). Complete recovery after one month was documented in 107 (69.6\%) of TA treated joints and $96(69.5 \%)$ of TH treated joints $(P=$ 0.232). However, rate of relapse after 3 months was significantly higher for TA treated joints (27 (20.1\%) vs. $13(8.8 \%)$, respectively, $P<0.01)$. No AEs were documented except minor scars at four joint injection sites.

Conclusion: The recovery from arthritis was similar $(\sim 70 \%)$ with both regimens, however relapse rate was more than double in TA as compared to TH injected joints. These findings are important due to a contemporary shortage of TH in the US market.
\end{abstract}

Keywords: Juvenile idiopathic arthritis, Intra-articular corticosteroids, Triamcinolone

\footnotetext{
* Correspondence: gamarilyo@clalit.org.il

${ }^{2}$ Sackler Faculty of Medicine, Tel Aviv University, Tel Aviv, Israel

${ }^{9}$ Pediatric Rheumatology Unit, Schneider Children's Medical Center of Israel, Petach Tikva, Israel

Full list of author information is available at the end of the article
}

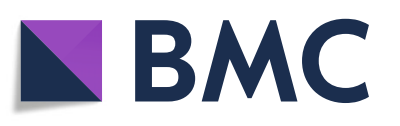

(- The Author(s). 2022 Open Access This article is licensed under a Creative Commons Attribution 4.0 International License, which permits use, sharing, adaptation, distribution and reproduction in any medium or format, as long as you give appropriate credit to the original author(s) and the source, provide a link to the Creative Commons licence, and indicate if changes were made. The images or other third party material in this article are included in the article's Creative Commons licence, unless indicated otherwise in a credit line to the material. If material is not included in the article's Creative Commons licence and your intended use is not permitted by statutory regulation or exceeds the permitted use, you will need to obtain permission directly from the copyright holder. To view a copy of this licence, visit http://creativecommons.org/licenses/by/4.0/. The Creative Commons Public Domain Dedication waiver (http://creativecommons.org/publicdomain/zero/1.0/) applies to the data made available in this article, unless otherwise stated in a credit line to the data. 


\section{Introduction}

Intra-articular corticosteroid joint injection (IAJI) is one of the most prescribed medications for oligoarticular JIA [1]. In accordance with current 2019 American College of Rheumatology (ACR) clinical guidelines, IAJI is recommended as adjunct therapy for oligarticular and polyarticular JIA, especially when prompt disease control is needed [2,3]. Response to intraarticular glucocorticoids is usually good, and many patients with oligoarthritis enter complete remission [1]. Several steroid preparations with different pharmacological properties are available for intra-articular injections in children. The beneficial effects and its duration are affected by the pharmacological properties of the type of preparation. In general, compounds that are less soluble and absorbed more slowly maintain synovial levels for longer periods with prolonged effect, resulting in lower systemic glucocorticoid levels [4-7]. The longest acting IAJIs used in clinical practice are triamcinolone hexacetonide $(\mathrm{TH})$ and triamcinolone acetonide (TA) [4, 5]. It has been shown that the choice of steroid preparation depends on a variety of considerations such as commercial availability and the institution where the rheumatologist was trained $[8,9]$. Several studies comparing the effectiveness of $\mathrm{TH}$ and other steroid preparations, including TA in children with JIA, have demonstrated the superiority of $\mathrm{TH}$ in terms of longer duration of action [4, 9-13]. However, TA is still used in many pediatric rheumatology centers [14]. Our rheumatology unit has experience with both regimens based on the availability of these drugs, and therefore we aimed to compare the shortand long-term efficacy and safety of TA versus TH for patients with oligo and poly-articular JIA.

\section{Methods}

\section{Study design and patients}

This is a retrospective chart review. We reviewed medical charts of children who fulfilled the ILAR revised diagnostic criteria for persistent/extended oligoarticular or polyarticular JIA [15], and had been treated with IAJI injection at Schneider Children's Medical Center's rheumatology unit during 2010-2019. Patients who had other chronic rheumatological illness, previous IAJI treatments in the last 4 months, or previous severe adverse reactions to steroids were excluded from the study.

Our pediatric rheumatology unit used TA for IAJI in JIA patients until May 2016, when TA was replaced by $\mathrm{TH}$ in June 2016 due to its availability and financial considerations. An intra-articular injection was performed according to clinical decision by a pediatric rheumatologist using standard protocol: prepare the skin with an antiseptic solution, aspirate the joint fluid to ensure the proper positioning of the needle, and then inject TA or $\mathrm{TH}$. We used recommended doses $[1,4,14]$. TH was used at a dose of $1 \mathrm{mg} / \mathrm{kg}$ (maximal dose of $40 \mathrm{mg}$ ) in knees, and $0.5 \mathrm{mg} / \mathrm{kg}$ (maximal dose of $20 \mathrm{mg}$ ) in ankles, elbows, and wrists. In smaller joints (wrist, midtarsal, and subtalar), $0.3 \mathrm{mg} / \mathrm{kg}$ (maximal dose of $10 \mathrm{mg}$ ) was injected. TA was used at a dose of $1-2 \mathrm{mg} / \mathrm{kg}$ (maximal dose of $80 \mathrm{mg}$ ) in knees, $0.5-1 \mathrm{mg} / \mathrm{kg}$ in ankles and elbows (maximal dose of $40 \mathrm{mg}$ ), and $0.3-0.5 \mathrm{mg} / \mathrm{kg}$ (maximal dose of $40 \mathrm{mg}$ ) in wrist, midtarsal, and subtalar joints. All children were sedated for the procedure. No local or intraarticular analgesics were used. The procedure was done without ultrasound guidance. Children were advised not to bear weight for $24 \mathrm{~h}$, and not to run or jump for another $48 \mathrm{~h}$.

\section{Clinical evaluation and outcomes}

Clinical assessment of arthritis was performed (as part of a clinical follow-up) by a pediatric rheumatologist at baseline, during the injection procedure, at $\sim 1$ month and $\sim 3$ months after the procedure, and at each followup visit thereafter. Complete response was defined as the absence of arthritis, and partial response as an improvement of arthritis (decrease in swelling or joint tenderness and/or increased range of motion). No response was defined as no change or worsening of arthritis. Primary outcome for efficacy was defined as full recovery from arthritis 1 month post IAJI, and relapse rate of arthritis 3 months post IAJI was defined as flare of arthritis after achieving complete response. Primary outcome for safety was defined as the occurrence of adverse events (AEs) during the follow-up period after IAJI. The AEs severity was classified according to the OMERACT 8 drug safety workshop [16].

The study was approved by the Research Ethics Board of Rabin Medical Center (approval no. RMC-18-0057).

\section{Data analysis}

The following parameters were analyzed: gender, age of disease onset, disease duration, JIA type, number of joints involved, type of joint injected, first/re-injection, and laboratory parameters at baseline (C-reactive protein (CRP), erythrocyte sedimentation rate (ESR), antinuclear antibodies (ANA) positive result (ANA $\geq 1: 40$ titer using Immunofluorescence exam), anti-CCP antibodies (in patients with polyarticular JIA $\geq 7$ years of age)), and concomitant therapy with NSAID's, methotrexate (MTX), or anti-tumor necrosis factor (TNF $\alpha)$ such as etanercept or adalimumab.

All results were expressed as mean and standard deviation (SD), median; and minimum and maximum, or frequency and percentage. The differences in patients' characteristics between the treatment groups were analyzed using chi-square test. Independent samples t-test or Mann-Whitney U test were used when normal distribution was not justified. The response rates for both 
treatment groups were compared using chi-square. The efficacy of intraarticular TA or TH injection was analyzed using the Kaplan-Meyer test, estimating the time of arthritis flare over a period of 40 months; missing data were censored. The analyses were performed by using SPSS software, version 25 (IBM, Chicago, Ill, USA), tests were two-tailed, and $p$ values $<0.05$ were considered statistically significant.

\section{Results}

The demographic, clinical, and laboratory parameters of both study groups are summarized in Table 1 . Of 102 patients in our study, $73 \%$ were females. The mean age of disease onset was 4 years, and mean disease duration at the time of treatment 1 year. Most (83\%) patients had persistent oligoarticular JIA, followed by extended oligoarticular and RF negative polyarticular JIA.

Of 292 joints injected the majority were in knees (61.6\%) and ankles (25\%), with 198 (67.8\%) joints injected for the first time. A total of 94 (32.2\%) joints were re-injected, 25 of them first with TA and when flared, re-injected with $\mathrm{TH}$.

Both groups were comparable for age of onset, disease duration, gender, mean number of joints per patient, type of joint injected, JIA subtype, laboratory parameters, and concurrent systemic therapy with MTX and anti-TNF $\alpha$ during and after IAJI. The rate of NSAID's given after IAJI was significantly higher in the TA group. Mean follow-up duration was 21.9 (range 4-95) months.

Table 1 Demographic, clinical and laboratory parameters of patients who received IAJI in both treatment groups

\begin{tabular}{|c|c|c|c|}
\hline & TA & $\mathrm{TH}$ & $P$ value \\
\hline Number of patients & 51 & 51 & \\
\hline Number of joints, $n(\%)$ & $138(47.3 \%)$ & $154(52.7 \%)$ & 0.44 \\
\hline Female, n(\%) & $37(72.5 \%)$ & $38(74.5 \%)$ & 0.50 \\
\hline Male, n(\%) & $14(27.5 \%)$ & $13(25.5 \%)$ & \\
\hline Age at onset (yr) mean \pm SD median & $4.39 \pm 3.422 .97$ & $4.18 \pm 3.163 .01$ & 0.76 \\
\hline Disease duration per joint, yr, mean (range) & $0.9(0.086-6.84)$ & $1.14(0.07-9.30)$ & 0.331 \\
\hline \multicolumn{4}{|l|}{ JIA subtype, $n(\%)$} \\
\hline Persistent oligoarticular & $42(82.4 \%)$ & $43(84.3 \%)$ & 0.85 \\
\hline Extended oligoarticular & $6(11.8 \%)$ & $5(9.8 \%)$ & \\
\hline RF negative polyarticular & $3(5.9 \%)$ & $3(5.9 \%)$ & \\
\hline \multicolumn{4}{|l|}{ Laboratory parameters at baseline: } \\
\hline $\mathrm{CRP}(\mathrm{mg} / \mathrm{dL})$ mean \pm S.D. median & $( \pm 1.3) 0.8$ & $1.3( \pm 1.2) 0.94$ & 0.47 \\
\hline ESR $(\mathrm{mm} / \mathrm{hr})$ mean \pm S.D. median & $29.8( \pm 17.3) 28.5$ & $28.9( \pm 17.1) 24.5$ & 0.83 \\
\hline ANA positive (> 1:40) & $26(51 \%)$ & $31( \pm 60.8 \%)$ & 0.27 \\
\hline \multicolumn{4}{|l|}{ Type of joint injected, n(\%) } \\
\hline Knee & $85(61.6 \%)$ & $95(61.7 \%)$ & 0.45 \\
\hline Ankle & $33(23.9 \%)$ & $40(26 \%)$ & \\
\hline Wrist & $6(4.3 \%)$ & $11(7.1 \%)$ & \\
\hline Elbow & $11(8 \%)$ & $7(4.5 \%)$ & \\
\hline Other (fingers\& toes etc.) & $3(2.2 \%)$ & $1(0.6 \%)$ & \\
\hline Number of joints first injected, n(\%) & $98(71 \%)$ & $100(64.9 \%)$ & 0.162 \\
\hline Number of joints re-injected, n(\%) & $40(29 \%)$ & $54(35.1 \%)$ & \\
\hline \multicolumn{4}{|l|}{ Systemic treatment (per injection), n(\%) } \\
\hline NSAID's TX during injection & $106(76.8 \%)$ & $125(81.2 \%)$ & 0.220 \\
\hline NSAID's after injection & $51(37 \%)$ & $33(21.4 \%)$ & $0.003^{*}$ \\
\hline MTX during injection & $14(10.1 \%)$ & $14(9.1 \%)$ & 0.457 \\
\hline MTX after injection & $53(38.4 \%)$ & $49(31.8 \%)$ & 0.146 \\
\hline Anti TNFa during injection & $3(2.2 \%)$ & $3(1.9 \%)$ & 0.605 \\
\hline Anti TNFa after injection & $20(14.5 \%)$ & $31(20.1 \%)$ & 0.133 \\
\hline
\end{tabular}

TA Triamcinolone acetonide, TH Triamcinolone hexacetonide, RF Rheumatoid Factor, NSAID'S Non-Steroidal Anti-inflammatory drugs, MTX Methotrexate "Significance: $P<0.05$ 
One patient with polyarticular JIA was older than 7 years old. His anti-CCP antibodies level was normal.

Patients with overall twenty eight joints (14 in each treatment group) were additionally treated with systemic MTX during the time of injection procedure. In 6/28 joints, the therapy was started 6-12 weeks prior the IAJI. Among them 2 joints had not relapsed in the study period. Patients with overall 6 joints (3 in each treatment group) were treated with anti TNF $\alpha$ during the time of IAJI procedure. in $3 / 6$ joints the therapy was started $6-$ 12 weeks prior the IAJI (18 months for 2 joints and 4 months for 1 joints). Among them 2 joints had not relapsed in the study period and 1 joint had relapsed 7 months after the injection.

Table 2 summarizes the differences in response rate for both treatment groups. Response rate at one month after injection was similar in both groups. Complete response, defined as absence of arthritis, was also similar in both groups $(69.6 \%$ vs. $69.5 \%$, respectively, $P=0.232$ ). Partial response, defined as an improvement of arthritis, was seen in 23.2 and $16.9 \%$ of patients in the $\mathrm{TA}$ and $\mathrm{TH}$ groups, respectively, $P=0.232$. No response or worsening was seen in 7.2 and $11.7 \%$, respectively, $P=0.232$. As seen in Table 2, most joints maintained complete response at 3 months after injection, however relapse rate after 3 months was significantly higher in the TA treated joints (20.1\% vs. $8.8 \%$, respectively, $P=0.018$ ).

Kaplan-Meyer analysis, which compared the efficacy of intraarticular TA or TH injection over a period of 40 months (Fig. 1), showed a significant higher relapse rate in TA vs. TH treated joints from 3 months after injection and throughout the follow-up period $(p<0.02)$. Logistic regression model showed the odds ratio for relapse was 2.24 (95\% CI $1.39-3.58, p=0.001)$ when using TA for IAJI.

Mild adverse reactions, such as skin atrophy or hypopigmentation at the injection site, were seen in only 4/292 (1.4\%) of injected joints, for two joints in each group. No other complications, such as joint infection or chemical synovitis, were noted.

\section{Discussion}

Although studies show better long-term efficacy of $\mathrm{TH}$ vs. TA, there is a paucity of data regarding the short-term efficacy of both drugs [9, 11-13]. Therefore, by counting on personal experience, the treating physician may be misled by assuming that TA and TH have overall similar efficacy. Our study shows that both TA and TH have similar efficacy 1 month after IAJI (i.e., induction of remission). However, after 3 months, the relapse rate of arthritis was significantly lower in the TH group as compared to the TA group ( $8.8 \%$ vs. $20.1 \%$, respectively, $P=0.018)$. Moreover, this trend was sustained during the 40-month follow up with an odds ratio to relapse more than double [2.24 (CI 1.39-3.58)] in TA injected joints.

As previously noted, earlier studies have addressed the long-term efficacy of TH vs. TA in JIA patients who received IAJI. Zulian et al. noted, in a prospective study, a significantly higher rate of response with $\mathrm{TH}$ than with TA at 6 months, 12 months, and 24 months $(60 \%$ vs. $33.3 \%$, respectively) [12]. Although not mentioned directly in their manuscript, a Kaplan Meier curve showed similar efficacy of TH and TA at 1 month after injection. The same group later showed similar long-term results in a blinded prospective study of symmetrical IAJI, where one joint was treated with $\mathrm{TH}$ and the other with TA [9]. In addition, it was shown that even when TA was given at a dose twice that of TH $(2 \mathrm{mg} / \mathrm{kg}$ vs $1 \mathrm{mg} /$ $\mathrm{kg}$ accordingly) in symmetrical involved joints, TH was more effective than TA during short- and long-term follow up [9]. Another study by Eberhard et al. compared time to relapse in a follow up of 15 months after TH or TA injection of 227 joints. At 6 months, they showed a response rate of $76 \%$ vs. $56 \%$, respectively. However, the effect of TA, but not $\mathrm{TH}$, appeared to subsequently wane, with a response rate of approximately $50 \%$ in the TH group vs. only $21 \%$ in the TA group after 12 months [13]. In addition, they found the hazard ratio attributed to the injection type was 1.8 (95\% CI 1.05, 3.08). Unlike our study and the Zulian group studies [9, 12], their TA group had a higher relapse rate starting in the first month after injection.

Table 2 Comparison of response rate between JIA patients in both treatment groups

\begin{tabular}{|c|c|c|c|c|c|c|}
\hline & \multicolumn{3}{|c|}{ Response at 1 month } & \multicolumn{3}{|c|}{ Response at 3 months ${ }^{\&}$} \\
\hline & $\mathrm{TA}$ & TH & $p$-value & TA & TH & $p$-value \\
\hline Complete response & $96(69.6 \%)$ & $107(69.5 \%)$ & 0.232 & 93 (69.4\%) & 107 (72.3\%) & $0.018^{*}$ \\
\hline Partial response & $32(23.2 \%)$ & $26(16.9 \%)$ & & $8(6.0 \%)$ & $18(12.2 \%)$ & \\
\hline No response & $10(7.2 \%)$ & $18(11.7 \%)$ & & $6(4.5 \%)$ & $10(6.8 \%)$ & \\
\hline Relapse & NA & NA & & $27(20.1 \%)$ & $13(8.8 \%)$ & \\
\hline
\end{tabular}

TA Triamcinolone acetonide, $T H$ Triamcinolone hexacetonide

At 3 months after IAJl, no information was available for four joints in the TA group and three joints in the TH group

"Significance: $P<0.05$ 


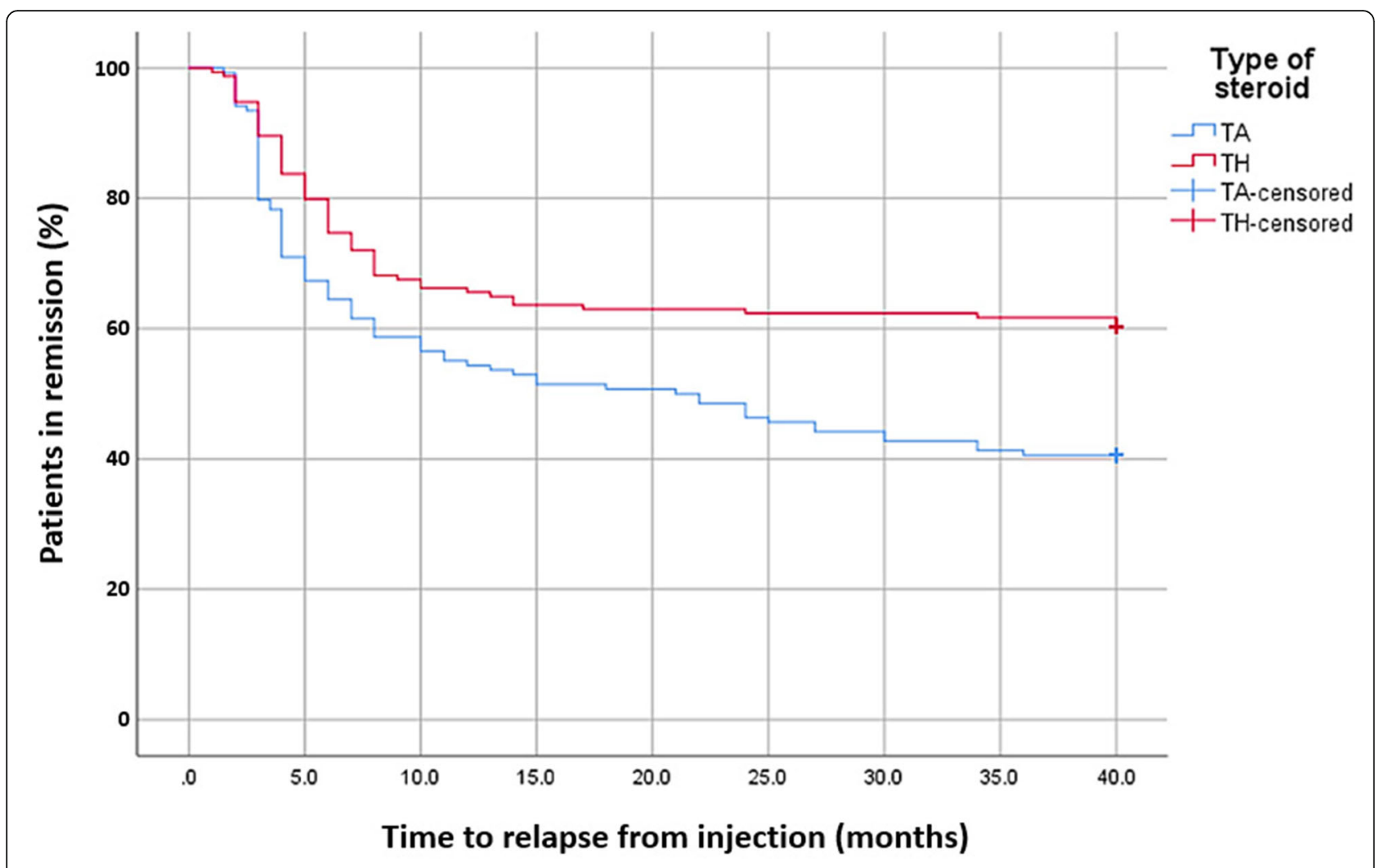

Fig. 1 Kaplan-Meyer analysis of relapse rates in both treatment groups ( $P=0.02$, log rank test) TA - Triamcinolone acetonide; TH - Triamcinolone hexacetonide

In our study, patients with overall 34 joints were treated additionally with systemic therapy of either MTX or TNFa during the IAJI time. However, groups were balanced (17 patients in $\mathrm{TH}$ and 17 in TA). Moreover, in sensitivity analysis, results were comparable with the study findings.

Interestingly, patients with $\mathrm{TH}$ injected joints were more likely to be treated with anti TNF $\alpha$ as compared to patient treated with TA (31 vs. 20, respectively), presumably due to better TNF $\alpha$ availability. None the less, these differences were not significant $(p=0.133)$.

Of note, no correlation was found between disease duration to the outcome of the first injection in both treatment groups.

IAJI is an important adjunct therapy in oligo-articular and polyarticular JIA that can serve as optimal initial therapy in oligoarticular JIA. The intraarticular approach delivers a high concentration of corticosteroid to the synovial fluid of the inflamed joint, there they influence different immunological functions, eventually reducing the migration of leukocytes into the joint $[5,7]$.

$\mathrm{TH}$ and TA are the most commonly used long-acting steroids for intra-articular injection. TH (molecular weight 532.66) differs from TA (molecular weight 434.49) by an alteration of one side chain, which presumably makes $\mathrm{TH}$ less water soluble as compared with
TA. Compounds with lower water solubility maintain effective synovial levels, thus providing longer duration of effectiveness within the peripheral joint space [5, 7]. Additionally, compounds with lower solubility are absorbed more slowly, resulting in lower peak plasma minimizing systemic effects such as adrenal suppression $[17,18]$. Indeed, pharmacokinetic studies show that due to its lower solubility, TH is absorbed more slowly than TA, maintaining synovial levels for a longer period (6 and 3.2-4.3 days, respectively) and creating lower systemic glucocorticoid levels [7]. This may explain the similar very short-term efficacy of both drugs vs. the higher relapse rate that was found in TA compared to $\mathrm{TH}$ injections. Furthermore, pharmacokinetic studies have shown that $40 \mathrm{mg}$ of $\mathrm{TA}$ is equivalent to $20 \mathrm{mg}$ of $\mathrm{TH}$ with regard to biological effect [7]. Many centers are still using TA in their clinical practice, mostly due to financial considerations and drug availability. Moreover, due to lack of practice guidelines, there are considerable variations of the dosages used in pediatric rheumatology centers around the globe for both regimens [14]. The price difference between both regimens is negligible (around $1.5 \mathrm{USD} / \mathrm{mg}$ for TH vs. $0.5 \mathrm{USD} / \mathrm{mg}$ for TA). Our rheumatology unit has experience with both steroid preparations and the decision to use a specific formulation is generally based on availability of either drug in 
out hospital. This provided an opportunity to compare the short- and long-term effectiveness of TA compared to $\mathrm{TH}$.

Although IAJI can be an effective and safe line of treatment, repeated intra-articular steroid injections may predispose to charcot's arthropathy as a potential side effect [19]. In our study, adverse events were infrequent and mild, including skin atrophy and hypopigmentation at the injection site in only four (1.4\%) joints, two in each group. This rate is comparable with the incidence reported in the literature ranging from 2 to $8 \%[9,11$, $14,20]$.

Our study has several limitations. First, it is a retrospective study. Second, although this was the largest cohort reported to date, the number of injected joints was relatively small and not sufficiently powered. Third, our study is composed of a heterogeneous group of patients including a large portion with re-injected joints and patients treated with MTX or biological therapy during the study period. Yet, subgroup sensitivity analysis has not demonstrated significant differences among groups. Fourth, validated scoring systems such as Juvenile Arthritis Disease Activity Score (JADAS), were lacking.

\section{Conclusions}

The recovery from arthritis was similar $(\sim 70 \%)$ with both regimens, however relapse rate (defined as flare of arthritis after achieving complete response) was more than double in TA as compared to $\mathrm{TH}$ injected joints. These findings are especially important due to the contemporary shortage of $\mathrm{TH}$ in the US market, and usage of TA in many pediatric rheumatology centers for IAJI around the globe.

\section{Abbreviations}

JIA: Juvenile idiopathic arthritis; IAJI: Intra-articular corticosteroids joint injection; TH: Triamcinolone hexacetonide; TA: Triamcinolone acetonide AE: Adverse events; ACR: American College of Rheumatology; CRP: C-reactive protein; ESR: Erythrocyte sedimentation rate; ANA: Antinuclear antibodies; NSAID's: Non-steroidal anti-inflammatory drugs; MTX: Methotrexate; TNF: Tumor necrosis factor

\section{Acknowledgements}

Not applicable.

\section{Authors' contributions}

SR - study conception and design, acquisition of data, interpretation of data, drafting the article; $\mathrm{O}$ - study conception and design, acquisition of data, OG - statistical analysis and interpretation of data, OP - analysis and interpretation of data, drafting the article, YG - statistical analysis of data, ZHW - Final approval of the version of the article to be published, YL interpretation of data, drafting the article and revising it, RT - Final approval of the version of the article to be published, $\mathrm{LH}$ - study design, revising the article, Final approval of the version of the article to be published, GA - study conception and design, drafting and revising the article, final approval of the article to be published. All authors read and approved the final manuscript.

\section{Funding}

No specific funding was received from any bodies in the public, commercial, or not-for-profit sectors to carry out the work described in this article.

\section{Declarations}

The study was approved by the Research Ethics Board of Rabin Medical Center (approval no. RMC-18-0057).

\section{Consent for publication}

Not applicable.

The datasets used and/or analysed during the current study are available from the corresponding author on reasonable request.

\section{Competing interests}

The authors declare that they have no competing interests.

\section{Author details}

${ }^{1}$ Pediatric Hematology Oncology Division, Schneider Children's Medical Center of Israel, Petach Tikva, Israel. ${ }^{2}$ Sackler Faculty of Medicine, Tel Aviv University, Tel Aviv, Israel. ${ }^{3}$ Department of Pediatrics C, Schneider Children's Medical Center of Israel, Petach Tikva, Israel. ${ }^{4}$ Pediatric Pulmonary Unit, Schneider Children's Medical Center of Israel, Petach Tikva, Israel.

${ }^{5}$ Department of Pharmacy, Schneider Children's Medical Center of Israel, Petach Tikva, Israel. ${ }^{6}$ The Department of Nursing, Ariel University, Ariel, Israel. ${ }^{7}$ Division of Ophthalmology, Tel Aviv Sourasky Medical Center, Tel Aviv, Israel. ${ }^{8}$ Department of Pediatrics B, Schneider Children's Medical Center of Israel, Petach Tikva, Israel. ${ }^{9}$ Pediatric Rheumatology Unit, Schneider Children's Medical Center of Israel, Petach Tikva, Israel.

Received: 30 August 2021 Accepted: 16 January 2022

Published online: 29 January 2022

\section{References}

1. Ringold S. Horneff G - Oligoarticular juvenile IdiopathicArthritis. In: Petty RE, Laxer RM, Lindsley CB, Wedderburn LR, Fuhlbrigge R, Mellins E, editors. Textbook of pediatric rheumatology, vol. 19. Philadelphia, PA: Elsiever; 2020. p. 241-9.

2. Beukelman T, Patkar NM, Saag KG, Tolleson-Rinehart S, Cron RQ, DeWitt EM, et al. American College of Rheumatology recommendations for the treatment of juvenile idiopathic arthritis: initiation and safety monitoring of therapeutic agents for the treatment of arthritis and systemic features. Arthritis Care Res. 2011;63(4):465-82. https://doi.org/10.1002/acr.20460.

3. Ringold S, Angeles-Han ST, Beukelman T, Lovell D, Cuello CA, Becker ML, et al. American College of Rheumatology/Arthritis Foundation guideline for the treatment of juvenile idiopathic arthritis: therapeutic approaches for non-systemic polyarthritis, Sacroiliitis, and Enthesitis. Arthritis Care Res. 2019; 71(6):717-34. https://doi.org/10.1002/acr.23870.

4. Hashkes PJ, Laxer RM. Medical treatment of juvenile idiopathic arthritis. JAMA. 2005;294(13):1671-84. https://doi.org/10.1001/jama.294.13.1671.

5. Genovese MC. Joint and soft-tissue injection. A useful adjuvant to systemic and local treatment. Postgrad Med. 1998;103(2):125-34. https://doi.org/10.3 810/pgm.1998.02.316.

6. Cleary AG, Murphy HD, Davidson JE. Intra-articular corticosteroid injection in juvenile idiopathic arthritis. Arch Dis Childhood. 2002;88(3):192-6. https:// doi.org/10.1136/adc.88.3.192.

7. Derendorf H, Möllmann H, Grüner A, Haack D, Gyselby G. Pharmacokinetics and pharmacodynamics of glucocorticoid suspensions after intra-articular administration. Clin Pharmacol Ther. 1986;39(3):313-7. https://doi.org/10.103 8/clpt.1986.45

8. Centeno LM, Moore ME. Preferred intraarticular corticosteroids and associated practice: a survey of members of the American College of Rheumatology. Arthritis Rheumatol. 1994;7(3):151-5. https://doi.org/10.1 002/art.1790070309.

9. Zulian F, Martini G, Gobber D, Plebani M, Zcchelo F, Manners P. Triamcinolone acetonide and hexacetonide intra-articular treatment of symmetrical joints in juvenile idiopathic arthritis: a double-blind trial. Rheumatology. 2004;43(10):1288-91. https://doi.org/10.1093/rheumatology/ keh313.

10. Balogh Z, Ruzsonyi E. Triamcinolone hexacetonide versus betamethasone. A double-blind comparative study of the long-term effects of intra-articular steroids in patients with juvenile chronic arthritis. Scand J Rheumatol. 1987; 67:80-2.

11. Gotte AC. Intra-articular corticosteroids in the treatment of juvenile idiopathic arthritis: safety, efficacy, and features affecting outcome. A 
comprehensive review of the literature. Open Access Rheumatol. 2009;1:3749. https://doi.org/10.2147/OARRR.S5103.

12. Zulian F, Martini G, Gobber D, Agosto C, Gigante C, Zacchello F. Comparison of intra-articular triamcinolone hexacetonide and triamcinolone acetonide in oligoarticular juvenile idiopathic arthritis. Rheumatology. 2003;42(10): 1254-9. https://doi.org/10.1093/rheumatology/keg358.

13. Eberhard BA, Sison MC, Gottlieb BS, llowite NT. Comparison of the intraarticular effectiveness of triamcinolone hexacetonide and triamcinolone acetonide in treatment of juvenile rheumatoid arthritis. J Rheumatol. 2004; 31(12):2507-12.

14. Dhanrajani A, Khubchandani RP. Joint injection practice variations in pediatric rheumatology - a global survey and call for action. Pediatr Rheumatol. 2020;18(1):81. https://doi.org/10.1186/s12969-020-00475-0.

15. Petty RE, Southwood TR, Manners P, Baum J, Glass DN, Goldenberg J, et al. International league of associations for rheumatology classification of juvenile idiopathic arthritis: second revision, Edmonton, 2001. J Rheumatol. 2004;31(2):390-2.

16. Woodworth T, Furst DE, Alten R, Bingham C, Yokum D, et al. Standardizing assesment and reporting of adverse effects in rheumatology clinical trials II: the rheumatology common toxicity criteria v.2.0. J Rheumatol. 2007;34(6): 1401-14.

17. Barnes PJ. Anti-inflamatory action of glucocorticoids: molecular mechanisms. Clin Sci. 1998;94(6):557-72. https://doi.org/10.1042/cs0940557.

18. Pearson D, Sheldon P. Effect of corticosteroid on lymphocyte adhesion. In: Mestecky J, Russell MW, Jackson S, Michalek SM, Tlaskalová-Hogenová H, Šterzl J, editors. Advances in mucosal immunology, advances in experimental medicine and biology book series, vol. 371. Boston, MA: Springer; 1995. p. 167-70. https://doi.org/10.1007/978-1-4615-1941-6_34.

19. Habib GS, Saliba W, Nashashibi M. Local effects of intra-articular corticosteroids. Clin Rheumatol. 2010;29(4):347-56. https://doi.org/10.1007/ s10067-009-1357-y.

20. Job-Deslandre C, Menkes CJ. Complications of intraarticular injections of triamcinolone hexacetonide in chronic arthritis in children. Clin Exp Rheumatol. 1990;8(4):413-6.

\section{Publisher's Note}

Springer Nature remains neutral with regard to jurisdictional claims in published maps and institutional affiliations.

Ready to submit your research? Choose BMC and benefit from:

- fast, convenient online submission

- thorough peer review by experienced researchers in your field

- rapid publication on acceptance

- support for research data, including large and complex data types

- gold Open Access which fosters wider collaboration and increased citations

- maximum visibility for your research: over $100 \mathrm{M}$ website views per year

At $\mathrm{BMC}$, research is always in progress.

Learn more biomedcentral.com/submissions 